\title{
Creative collaboration
}

Using the library to promote scholarship

ibraries have long been known for bring-

ing communities together. An ongoing commitment to this mission can be seen at the University of Kansas (KU), where the libraries recently developed an exhibits program, with the help of talented and experienced campus partners, designed to unite the research and scholarship of its community and showcase that work through an elegant, professional, and highly visible library gallery.

The KU Libraries Exhibits Program is a collaborative effort based on the understanding that all creative endeavors in the KU community are complemented and reinforced by the rich collections of the libraries. The vision for the exhibition program was articulated and developed in 2007 under the guidance of KU Dean of Libraries Lorraine Haricombe. Haricombe's goal was to solicit exhibitions both internal and external to the libraries that highlight the strength of the libraries' collections and promote the creative scholarship of our campus community. The program was to be run by committee: five members from the library faculty and staff, and one graduate student from the Museum Studies program. Three ex-officio appointments were made from the facilities, conservation, and communications/advancement departments. In addition, one faculty member, chosen from the KU Department of Design, was invited to serve as a committee member for the first year.

The committee was charged to:

- create an innovative exhibition space;

- collaborate with other peer institutions both on and off the KU campus;
- nourish intellectual, aesthetic, and creative growth;

- celebrate local and global accomplishments and events;

- promote nontraditional formats such as virtual, 3-D and other new media; and

- encourage scholarly and educational use of the KU Libraries.

In order to successfully develop this multifaceted interdisciplinary exhibits program, it was clear that we would need to draw on the knowledge and skills of our campus partners. Our goal was to expand knowledge about library collections, faculty and student scholarship, and our internal and external partners.

\section{Create an innovative space}

It has been my experience that artistic people can often be found working in libraries. In the KU Libraries we have poets, weavers, graphic designers, creative writers, wood carvers, musicians, quilters, and printmakers - to name just a few. Three members of the original exhibits committee had art degrees, but the creative thinking of the committee did not stop there. All members rose to the challenge of considering this new space in an imaginative, unexpected way. Our charge was to create a multipurpose and accessible gallery space in the middle of a busy study area on the central floor of the main library. The first time the committee walked to the far end of

Sarah Goodwin Thiel is associate librarian for digital imaging at the Center for Digital Scholarship at the University of Kansas Libraries, e-mail: sgthiel@ku.edu ๑ 2011 Sarah Goodwin Thiel 
the popular study area designated to hold the new gallery space, each member took a look around and wondered where to begin. "Why not change the wall colors, rip up the carpet, and take down the ceiling tiles to expose the pipes and duct work?" This would be the first of many suggestions we would receive from graphic design professor Jeremy Shellhorn to stretch our thinking about the new gallery. But others quickly joined in, and it was decided: we would build the gallery not by putting up walls, but through visual changes that would define the space.

In the end, black carpet squares replaced the blue patterned carpet in the 14-inch by 32-inch space designated as the Library Gallery. The ceiling tiles were not removed but instead replaced with new tiles, existing north and south walls of the gallery were repainted-one blue and the other gold, and graphics were considered for each wall to brand the space. The committee decided to create a gallery logo for the north wall and to select a quotation for the south wall, one that would beckon and inspire library visitors. We sent a call out to library and teaching faculty asking for recommendations and, in the end, settled of the following quote from Samuel Johnson:

\section{Curiosity is one of the} most permanent and certain characteristics of a vigorous mind.

\author{
Samuel Johnson
}

\section{Figure 1. Library Gallery quotation.}

When considering the design for our Library Gallery logo, we again looked to the talent and expertise of Jeremy Shellhorn. We spent a significant amount of time brainstorming about the design and how it would represent our vision for the gallery. We wanted something that would appeal to our wide audience base that included students, faculty, visiting scholars, and community visitors. In the end, Shellhorn came up with a design that gave us the bold brand we were looking for: combining old and new, fresh and formal, and pointing to the architecture of the building without competing for the attention of the students studying in the library.

Shellhorn's contribution to the Library Gallery design was tremendous. The professional quality of the site is due in large part to his skill as a designer. To have contacted with a design firm for this service would have been outside the cost limits of our project, plus, it would not have enabled the rich collaboration that was key to the success of the project. Not only did Shellhorn guide us through the large and small details of a challenging design project, he became our friend and colleague and developed a real understanding of our vision for the space. The success of the design was the result of many weeks of conversation and debate between seven people who came together through a shared interest to create a comfortable, flexible, long-lasting space to promote creative scholarship.

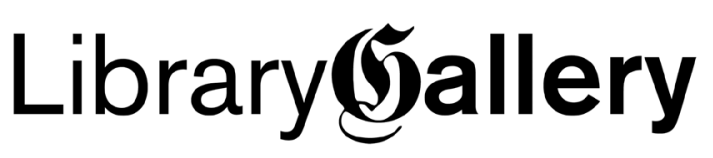

Figure 2. Library Gallery logo.

As we moved beyond the look and feel of the gallery into developing the effective and consistent quality of our new exhibition venue, we turned to our campus partner, the KU Spencer Museum of Art (SMA). SMA's exhibition team came to the library and consulted on our exhibition space with particular attention to lighting, display, and labeling issues.

The impact of our art partners on the final design of the Library Gallery cannot be overstated. When all was said and done, the gallery held five cases for analog material, a 52-inch plasma screen to display digital items, a stand-alone workstation for interactive materials and eight two-sided picture frames suspended from the ceiling for large format images. UV-filtered florescent lights in the ceiling are covered with 3/8th-inch lenses to diffuse the light and cut down on glare; original wooden, glass-topped cases 
were refinished and used for analog material; labels are consistently created following a standardized template; and the library gallery logo graces the wall of the gallery as well as all posters, flyers, and thank you notes distributed by the Exhibits Committee. There is also an accompanying Web site. This professional and gracious outcome would not have resulted without the unique creativity and

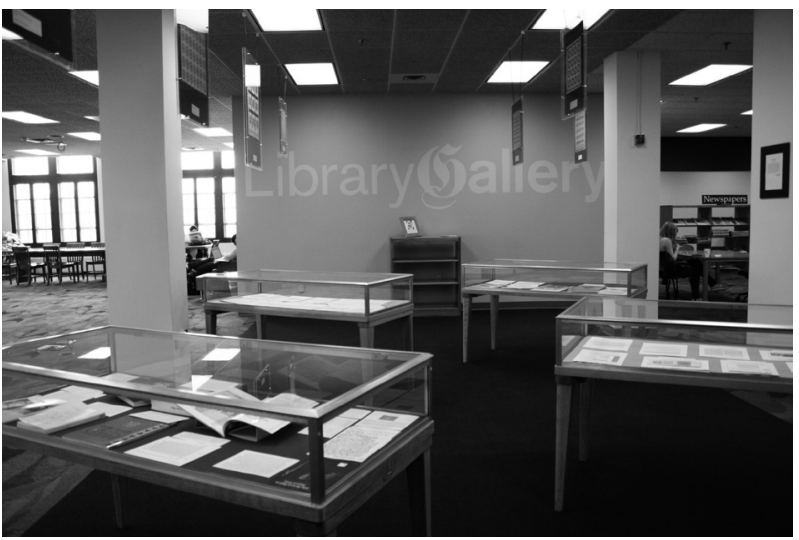

Library Gallery, north wall. Photo courtesy of KU Libraries. installed "Machine in a Void: World War I \& the Graphic Arts."

Museum staff members provide the library with several images from their own galler- knowledge of our art experts.

\section{Research snapshot}

Creating the Library Gallery was a complex challenge, but it was just the first phase of the Exhibits Program development and only the beginning of our continued partnership with SMA. Initially we chose topics that related to the museum's exhibition schedule because that schedule had been set several years in advance. By borrowing the museum's exhibition themes, we saw a way for the libraries to unite the scholarship on campus and show visitors that many campus resources existed around a chosen theme. The first three exhibitions installed in the library followed themes set by SMA: the first, held spring 2009, was entitled, "Environmental Change: An Interdisciplinary Perspective." It was based on the SMA exhibition installed the same semester, "Climate Change at the Poles." The second, "Reach Out: Scholarly and Visual Communication to Promote AIDS Awareness," was opened fall semester, 2009 and was based on the museum's exhibition "The Graphic Imperative: International Posters for Peace, Social Justice, and the Environment, 19652005." The third, "Research, Remembrances and Reflections of the Great War" was held spring semester 2010, when the museum tual goal through this partnership is to show visitors that KU has many collections surrounding a given topic and that a visit to the KU campus can and should include several stops. Discussions are underway between museum staff the Libraries Exhibits Committee concerning the development of a walking tour and map guiding visitors to the cultural heritage venues within walking distance to SMA and Watson Library.

We wanted to provide a "snapshot," as one faculty member put it, of the research generated by KU scholars and supported through the KU Libraries. We knew that materials in our exhibitions would represent only a small window into the KU-generated research surrounding our selected themes. But we hoped to pique the interest and imagination of our visitors. In preparation for our first exhibition on environmental change, a call was made to all librarians to consider their collections and whether they had material pertinent to that subject. In the end, three subject specialists volunteered to highlight the following collections and discuss how each related to the study of environmental science: business and economics, political science, and cartography. Each specialist suggested names of pertinent scholars, projects, and institutes and each selected 10 to 15 collection items 
for display along with label information, a bibliography, and a one-page bibliographer's/ archivist's statement. This statement described the strengths and relevance of KU's research collection on the chosen topic. Similar to an Artist's Statement in a museum exhibition, the Bibliographer's Statement provides the specialist with the opportunity to showcase the collection as well as his or her depth of knowledge and understanding of the given subject.

We then worked to engage faculty members, alumni, and students by highlighting their research and scholarly efforts. KU scholars were identified from a wide range of disciplines, such as business and economics, art and design, geography, environmental studies, physics and world history, and were then invited to showcase their published work. The interdisciplinary nature of the program has proven critical to its success. It supports the basic mission of the libraries, to serve as “. . . dynamic partners and campus leaders in advancing

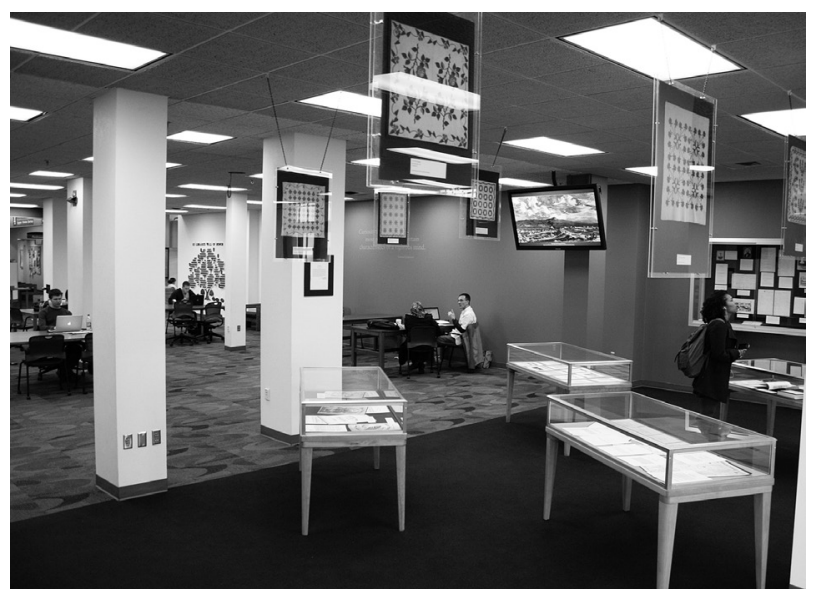

Library Gallery, south wall. Photo courtesy of KU Libraries.

partners whose missions are germane to our topic. Partners may include other cultural venues, student clubs, campus research centers, or related community organizations. The digital format is critical to our ability to showcase the work of our partners. Because the Library Gallery does not have 24-hour dedicated security, we do not display primary resource materials. This means that partners supply us with digital images of their original items, which we either print and display with the analog materials or add to the slide show that runs on the gallery plasma screen. As we have done with SMA, flyers and brochures are exchanged and information about the respective efforts and events of each partner can be found on all of our Web sites. With the "Aids Awareness" exhibition, we partnered with the Douglas County Aids Project (DCAP), Lawrence, Kansas, and the Kansas AIDS Education Training Center (KAETC), Wichita, Kansas.

For the "Reflections on WWI" exhibition, we partnered with the Haskell Indian Nations University in Law-

inquiry and learning for $\mathrm{KU}$, for the state of Kansas, and for an ever-expanding community of world scholars." By highlighting the work of selected faculty and students, the libraries remind exhibit visitors of KU's strength as a research institution and, at the same time, reminds academic departments that the KU Libraries are their partners and friends.

Providing a scholarly snapshot of a particular research topic also creates an opportunity to collaborate with other organizations, both on and off campus. With every exhibition we install, we first identify internal and external rence and the National World War I Museum in Kansas City, Missouri. The result of these collaborations? Our snapshot becomes more robust and the collections and research of our partners is promoted in a new and effective way.

In the second year of the program, we began inviting a speaker to present at the opening reception of each exhibition. Again, it is another way to promote the knowledge and skills of KU community members. Each speaker is asked to talk about his or her research and to mention, briefly, the way libraries have assisted his or her work. Not 


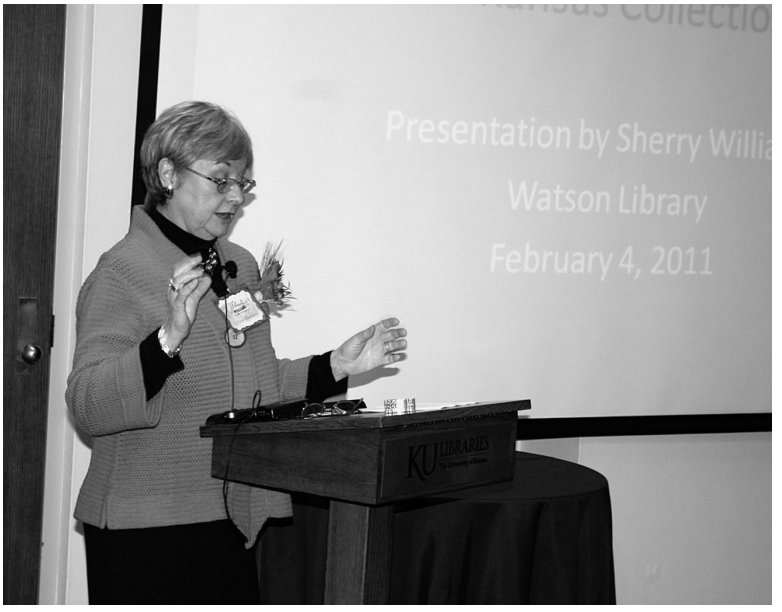

Kansas Collection Curator, Sherry Williams, speaking at the "1861: Kansas from Statehood to Civil War"opening reception, 2011. Photo courtesy of KU Libraries.

surprisingly, libraries have played a key role in the research journeys of all of our speakers and they are pleased to talk about how critical that role is. This has added great value to our opening reception program and is enjoyed by all attending.

\section{Bringing it all together}

We have seen conclusively the fruitful and productive results of our partnership with the KU Arts community. Our ambitious goal to create an elegant, professional, and highly visible gallery was brought to fruition as a result of this partnership, and the resulting space continually succeeds in bringing together and celebrating the scholarship of our research partners. The outcome of the program's interdisciplinary focus has been both pleasurable and beneficial. Our outreach to colleagues has been met with enthusiasm. Without exception, everyone invited to showcase their work in the libraries has responded positively with quick praise for this outreach activity. Exhibitions in the Library Gallery have raised the libraries visibility and have allowed librarians and archivists to demonstrate their knowledge and expertise. In the short time the KU Libraries Exhibits Program has been in existence, many relationships have been realized and new partnerships born. The program successfully engages faculty, alumni and students by showcasing their research and builds effective partnerships with peer institutions by highlighting collections and encouraging future collaborations. $n$

\section{Statement of ownership and management}

College $\&$ Research Libraries News is published 11 times a year (monthly, combining July/August) by the American Library Association, 50 E. Huron St., Chicago, IL 60611 American Library Association, owner; David Free, editor. Second-class postage paid at Chicago, Illinois. Printed in the U.S.A. As a nonprofit organization authorized to mail at special rates (DMM Section 423.12), the purposes, function, and nonprofit status of this organization and the exempt status for federal income tax purposes, have not changed during the preceding 12 months.

Extent and nature of circulation. ("Average" figures denote the number of copies printed each issue during the preceding twelve months; "Actual" figures denote the number of copies of single issues published nearest to filing date.) Total number of copies (net press run): Average, 13,323; Actual, 13,530. Total paid/requested sub- scriptions: Average, 12,708; Actual, 12,881. Sales through dealers and carriers, street vendors, counter sales, and other non-USPS paid distribution: not applicable. Other classes mailed through the USPS: not applicable. Total paid and/or requested circulation: Average, 12,841 Actual, 12, 963. Free distribution by mail: Average, 98; Actual, 73. Free distribution outside the mail: Average, 0; Actual, 0. Total free distribution: Average, 118; Actual, 67. Total distribution: Average, 12,841; Actual, 12,963. Copies not distributed: Office use, leftover, spoiled: Average, 482; Actual, 567. Total (sum of previous entries): Average, 13,323; Actual, 13,530. Percent paid and/or requested circulation: Average, 99.5\%; Actual, 95.2\%.

Statement of ownership, management, and circulation (PS Form 3526, September 2007) for 2011 filed with the United States Postal Service, Postmaster in Chicago, Illinois, August 1, 2011 